\section{(2) \\ BRAZILIAN JOURNAL \\ OF MEDICAL AND BIOLOGICAL RESEARCH}

www.bjournal.com.br
ISSN 1414-431X

Volume 45 (11) 995-1101 November 2012

BIOMIDICAL SCIENCES

AND

CLINICAL INVESTIGATION

Braz J Med Biol Res, November 2012, Volume 45(11) 1052-1059

doi: $10.1590 / \mathrm{S} 0100-879 \mathrm{X} 2012007500125$

Rhein induces apoptosis of human gastric cancer SGC-7901 cells via an intrinsic mitochondrial pathway

Yiwen Li, Yuqing Xu, Bo Lei, Wenxiu Wang, Xin Ge and Jingrui Li

The Brazilian Journal of Medical and Biological Research is partially financed by

\section{Q QNPPq}

da Ciência e Tecnologia

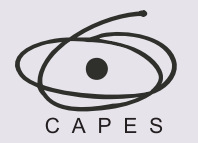

Ministério da Educação

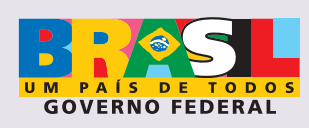

DTFAPESP

Institutional Sponsors

๑ SHIMADZU UNICAMP

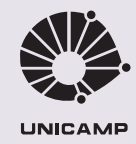

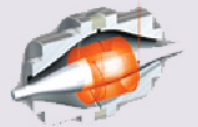

1DI Associaçăo Explore High - Performance MS Orbitrap Technology In Proteomics \& Metabolomics analitica $\underset{\text { analiticaweb.com.br }}{\text { Thermo }}$
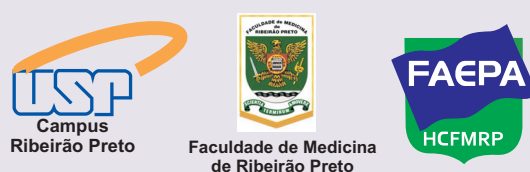


\title{
Rhein induces apoptosis of human gastric cancer SGC-7901 cells via an intrinsic mitochondrial pathway
}

\author{
Yiwen $\mathrm{Li}^{1}$, Yuqing $\mathrm{Xu}^{1}$, Bo Lei ${ }^{3}$, Wenxiu Wang ${ }^{1}, \mathrm{Xin} \mathrm{Ge}^{2}$ and Jingrui $\mathrm{Li}^{2}$ \\ 1Department of Oncology, Second Affiliated Hospital, Harbin Medical University, Nangang District, \\ Harbin, Heilongjiang, China \\ 2Department of General Surgery, Heilongjiang Province Hospital, Harbin, Heilongjiang, China \\ ${ }^{3}$ Department of Breast Surgery, Third Affiliated Hospital of Harbin Medical University, \\ Harbin, Heilongjiang, China
}

\begin{abstract}
Rhein is a primary anthraquinone found in the roots of a traditional Chinese herb, rhubarb, and has been shown to have some anticancer effects. The aim of the present study was to investigate the effect of rhein on the apoptosis of the human gastric cancer line SGC-7901 and to identify the mechanism involved. SGC-7901 cells were cultured and treated with rhein (0,50, 100,150 , and $200 \mu \mathrm{M}$ ) for 24,48 , or $72 \mathrm{~h}$. Relative cell viability assessed by the MTT assay after treatment was $100,99,85$, $79,63 \%$ for $24 \mathrm{~h} ; 100,98,80,51,37 \%$ for $48 \mathrm{~h}$, and 100, 97, 60, 36, 15\% for $72 \mathrm{~h}$, respectively. Cell apoptosis was detected with TUNEL staining and quantified with flow cytometry using annexin FITC-PI staining at $48 \mathrm{~h}$ after 100,200 and $300 \mu \mathrm{m}$ rhein. The percentage of apoptotic cells was $7.3,21.9,43.5 \%$, respectively. We also measured the mRNA levels of caspase- 3 and -9 using real-time PCR. Treatment with $100 \mu \mathrm{M}$ rhein for $48 \mathrm{~h}$ significantly increased mRNA expression of caspase-3 and -9 . The levels of apoptosis-related proteins including Bcl-2, Bax, Bcl-xL, and pro-caspase- 3 were evaluated in rhein-treated cells. Rhein increased the Bax:Bcl-2 ratio but decreased the protein levels of $\mathrm{Bcl}-\mathrm{xL}$ and pro-caspase-3. Moreover, rhein significantly increased the expression of cytochrome $c$ and apoptotic protease activating factor 1, two critical components involved in mitochondrial pathway-mediated apoptosis. We conclude that rhein inhibits SGC-7901 proliferation by inducing apoptosis and this antitumor effect of rhein is mediated in part by an intrinsic mitochondrial pathway.
\end{abstract}

Key words: Rhein, SGC-7901 cells; MTT; TUNEL; Flow cytometry; Apoptosis

\section{Introduction}

Gastric cancer remains the fourth most common malignancy and one of the leading causes of cancer-related deaths, even though gastric cancer mortality has decreased markedly over the last 50 years worldwide $(1,2)$. Surgical resection of the primary tumor and regional lymph nodes is the first choice of treatment for gastric cancer and additive chemotherapy combined with surgery is frequently needed for patients with high-risk gastric cancer. However, these traditional chemotherapeutic approaches have serious side effects and are not applicable to all patients.

Recent studies have focused on the antitumor properties of natural products because of their confirmed pharmacological properties and few side effects. Rhein (4,5-dihydroxyanthraquinone-2-carboxylic acid), a primary anthraquinone present in the roots of rhubarb (Rheum palmatum L. or $R$. tanguticum Maxim.), is a traditional Chinese herb medicine that has been used as a laxative and stomach drug for years $(3,4)$. Recently, in vivo studies have shown that rhein inhibits the growth of tumor cells in rat liver (5), human glioma (6) and Ehrlich ascites tumor (7). Other in vivo and in vitro studies have also shown that rhein inhibits the growth of many cancer cells, such as SCC-4 human tongue cancer cells (8-10), Caco-2 human adenocarcinoma cells (11), breast cancer cells (12), nasopharyngeal carcinoma cells (13), A-549 human lung cells (14), human hepatocellular carcinoma BEL-7402 cells (15), and human cervical cancer Ca Ski cells (16). However, little is known about the effect of rhein on the growth of human gastric cancer cells.

Apoptosis is the most important pathway through which

Correspondence: Wenxiu Wang, Department of Oncology, Second Affiliated Hospital, Harbin Medical University, 246 Xuefu Road, Nangang District, Harbin, Heilongjiang, 150086, China. Fax: +086-0451-8660-5264. E-mail: wangwenxiu150086@163.com 
many compounds exert their antitumor effects. It has been shown that rhein can induce apoptosis by increasing nuclear condensation and DNA fragmentation (8), activating caspase-8, -9 , and -3 (8), increasing the levels of Fas, p53, p21, and Bax, but decreasing the levels of Bcl-2 (16). Whether rhein induces apoptosis in gastric cancer cells through the same signal pathway remains a question to be addressed. The aim of the present study was to investigate the potential anticancer effects of rhein on human gastric cancer cells and the underlying molecular mechanisms.

\section{Material and Methods}

\section{Chemicals and reagents}

Rhein and MTT [3-(4,5-dimethylthiazol-2-yl)-2,5-diphenyltetrazolium bromide] were obtained from Sigma Chemical Co. (USA). The TUNEL staining kit was purchased from the Beyotime Institute of Biotechnology (China). Annexin V/ propidium iodide $(\mathrm{PI})$ was purchased from Biosea (China). The primers of caspase- 9 and -3 for real-time PCR were designed according to the CDS of Homo sapiens caspase-9 and -3 from Pubmed and were synthesized by GenScript (China). Moloney murine leukemia virus (M-MLV) reverse transcriptase and relevant reagents for RT-PCR were purchased from Promega Corporation (USA). Antibodies against $\mathrm{Bcl}-2$, Bax, $\mathrm{Bcl}-\mathrm{xL}$, cytochrome $\mathrm{c}$, apoptotic protease activating factor 1 (Apaf-1), caspase- 3 and $\beta$-actin were purchased from Cell Signaling Technology (USA). The Trizol reagent kit and fluorescence-conjugated secondary antibodies were purchased from Invitrogen (USA). Other chemicals were obtained in their commercially available highest purity grade.

\section{Cell culture}

Human gastric cancer line SGC-7901 cells were obtained from the cell line bank of the Chinese Academy of Sciences. Cells were cultured in complete RPMI-1640 medium (Hyclone, USA) supplemented with 10\% heat-inactivated bovine serum (Gibco, USA), $100 \mathrm{U} / \mathrm{mL}$ penicillin and 100 $\mu \mathrm{g} / \mathrm{mL}$ streptomycin at $37^{\circ} \mathrm{C}$ in a humidified atmosphere with $5 \% \mathrm{CO}_{2}$.

\section{MTT assay for cell proliferation}

The SGC-7901 cells were seeded onto a 96-well culture plate at 5000 cells/well for $16 \mathrm{~h}$ for attachment and then treated with $0,50,100,150$, or $200 \mu \mathrm{M}$ rhein for 24,48 , or $72 \mathrm{~h}$, respectively. MTT dye was added to each well and incubated at $37^{\circ} \mathrm{C}$ for $4 \mathrm{~h}$. The supernatant was then discarded and purple-colored formazan precipitates were dissolved in $150 \mu \mathrm{L}$ dimethyl sulfoxide. After complete dissolution, absorbance was measured at $490 \mathrm{~nm}$ on a multi-well plate reader. The effect of rhein on growth inhibition was assessed as percent inhibition of cell growth. The background absorbance of the medium in the absence of cells was subtracted. Percent viability was calculated as [value of drug-treated group (A)/ control group (A)] x 100\%. Each assay was carried out three times, and the results are reported as means \pm SEM.

\section{Detection of apoptotic cells by TUNEL staining}

The apoptotic SGC-7901 cells were detected by the TUNEL assay, which was performed using an in situ Nick-End Labeling kit. Cells were treated with rhein $(0-300 \mu \mathrm{M})$ for $48 \mathrm{~h}$ on 96 -well plates. The attached cells were then washed with PBS and fixed in freshly prepared $4 \%$ paraformaldehyde for $30 \mathrm{~min}$. The cells were then washed twice with PBS and incubated with digoxigenin-conjugated deoxyuridine triphosphate in a terminal deoxynucleotidyl transferase-catalyzed reaction for $1 \mathrm{~h}$ at $37^{\circ} \mathrm{C}$ in a humidified atmosphere. The cells were then immersed in stop/wash buffer for $10 \mathrm{~min}$ at room temperature, washed with PBS, and incubated with a peroxidase-conjugated anti-digoxigenin antibody for $30 \mathrm{~min}$. The nucleic fragments were stained with 3,3'-diaminobenzidine as a peroxidase substrate for 5 min. Apoptotic cells stained brown.

\section{Quantification of apoptosis by flow cytometry}

The apoptosis of SGC-7901 cells was quantified by flow cytometry. After incubation with various concentrations of rhein for $48 \mathrm{~h}$, the cells were harvested by Trypsin treatment and centrifugation, washed with PBS, stained with annexin V-FITC and PI according to manufacturer protocol, and then analyzed with a Becton FACSC flow cytometer (Becton Dickinson Corporation, USA). For each condition, $1 \times 10^{4}$ cells were studied in each cytometry experiment.

\section{RNA isolation and quantitative real-time RT-PCR analysis}

Total cell RNA was extracted with a Trizol reagent kit. The quality of each RNA sample (including its concentration and purity) was checked by measuring the absorbance. One microgram RNA from each sample was used to generate cDNA using M-MLV reverse transcriptase according to manufacturer specifications. After an initial denaturation step at $95^{\circ} \mathrm{C}$ for 10 min using SYBR Green PCR Master Mix (Applied Biosystems, USA), real-time PCR was cycled 40 times between $95^{\circ} \mathrm{C} / 15 \mathrm{~s}$ and $60^{\circ} \mathrm{C} / 1 \mathrm{~min}$. Amplification was performed using the 7500 fast real-time PCR system (Applied Biosystems) and the products were routinely checked using dissociation curve software. Transcript quantities were compared by the relative Ct method and the amount of caspase- 3 and -9 was normalized to the endogenous control (GAPDH). The value in relation to the control sample was given by $2-\Delta \Delta C T$. Real-time PCR primer sequences for caspase measurements were as following: caspase-3 (sense: 5'-TGGTTCATCCAGTCGCTTTG-3' and antisense: 5'-CATTCTGTTGCCACCTTTCG-3'); caspase-9 (sense: 5'-CGAACTAACAGGCAAGCAGC-3' and antisense: 5'-ACCTCACCAAATCCTCCAGAAC-3'). 


\section{Western blot analysis}

Following rhein treatment, SGC-7901 cells were washed twice with ice-cold PBS and collected in lysis buffer including $50 \mathrm{mM}$ Tris, $\mathrm{pH} 7.4,150 \mathrm{mM} \mathrm{NaCl}, 1 \% \mathrm{NP}-40,0.25 \%$ sodium deoxycholate, $0.1 \%$ SDS, $1 \mathrm{mM} \mathrm{Na}_{3} \mathrm{VO}_{4}, 1 \mathrm{mM} \mathrm{NaF}, 1 \mathrm{mM}$ EDTA, $1 \mathrm{mM}$ PMSF and $1 \mu \mathrm{g} / \mathrm{mL}$ leupeptin. The supernatant was obtained by centrifugation at $12,000 \mathrm{~g}$ for $20 \mathrm{~min}$. Total protein concentration was determined by the Bradford assay. For immunoblotting, $100 \mu \mathrm{g}$ protein from each sample was subjected to electrophoresis on $12 \%$ SDS-PAGE and the separated proteins were transferred onto a nitrocellulose membrane. The nitrocellulose membrane was blocked with $5 \%$ non-fat milk powder $(\mathrm{w} / \mathrm{v})$ at room temperature for $2 \mathrm{~h}$, then incubated with the primary antibodies against Bcl-2 (1:200), Bax (1:200), Bcl-xL (1:200), cytochrome c (1:200), Apaf-1 (1:200), caspase-3 (1:200), and $\beta$-actin (1:500), respectively, at $4^{\circ} \mathrm{C}$ overnight. After washing, the membrane was incubated with fluorescence-conjugated secondary antibody (anti-rabbit or anti-mouse 1:10,000; Invitrogen) at room temperature for $50 \mathrm{~min}$. $\beta$-actin was used as an internal control to monitor equal protein loading and transfer of proteins from the gel to the membranes after stripping them with the $\beta$-actin antibody. Western blot bands were quantified using the Odyssey infrared imaging system (LI-COR, USA). The results represent three independent experiments.

\section{Statistical analysis}

Data are reported as the means \pm SEM of at least three independent experiments. For statistical analysis, one-way ANOVA was used for comparison of one variance among groups and two-way ANOVA was used for comparison of two independent variances among groups followed by the Tukey post hoc test. A P value less than 0.05 was considered to be significant.

\section{Results}

\section{Rhein-induced morphological changes and anti-proliferation of SGC-7901 cells}

The morphology of the SGC-7901 cells was examined using a phase contrast microscope. The control group cells displayed normal morphology with a typical polygonal and cobblestone monolayer appearance, plump cell body, clear cell boundary, and transparent cytoplasm (data not shown). In the presence of Rhein, SGC-7901 cells showed round morphology with small wrinkles and broken debris, suggesting rhein-induced toxicity to SGC-7901 cells. SGC-7901 cells were incubated with rhein at $0,50,100,150$, and 200 $\mu \mathrm{M}$ and cell viability was evaluated by the MTT assay at 24 , 48 , and $72 \mathrm{~h}$. Treatment with $50 \mu \mathrm{M}$ rhein had no effect on SGC-7901 proliferation at any tested time, while treatment with 100,150 , and $200 \mu \mathrm{M}$ rhein significantly reduced cell viability compared to the control group (Figure 1), indicating a dose-dependent effect of rhein on cell viability. Incubation with rhein for $72 \mathrm{~h}$ showed the maximum inhibition for each dose. Among all the tests, cells incubated with $200 \mu \mathrm{M}$ rhein for $72 \mathrm{~h}$ showed the highest anti-proliferation effect, with cell viability decreasing to $15 \%$ of the control cells. This result suggests that rhein inhibits the proliferation of SGC-7901 cells in a dose- and time-dependent manner.

\section{Rhein-induced apoptosis of SGC-7901 cells}

The TUNEL apoptosis detection kit was used $48 \mathrm{~h}$ after cells were treated with $0,100,200$, or $300 \mu \mathrm{M}$ rhein. Representative images of TUNEL staining are shown in Figure 2.

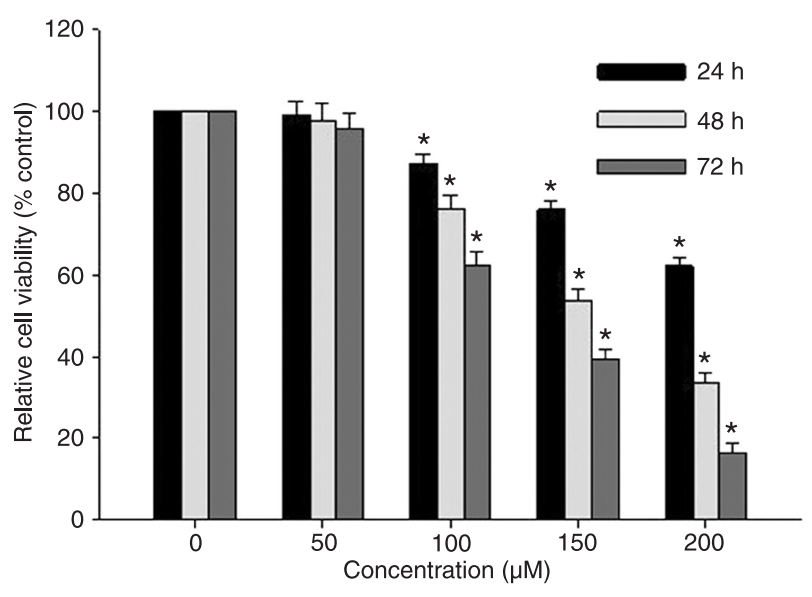

Figure 1. Rhein-induced anti-proliferation of SGC-7901 cells. SGC-7901 cells were treated with rhein at doses of $0,50,100$, 150 , or $200 \mu \mathrm{M}$ for 24,48 , and $72 \mathrm{~h}$. Cell viability was evaluated with the MTT assay and results are reported as relative cell viability (\%). All data were normalized to the control group, which was considered to be $100 \%$. The results showed that rhein inhibited proliferation of SGC-7901 cells in a dose- and time-dependent manner. ${ }^{*} \mathrm{P}<0.05$ versus control group $(0 \mu \mathrm{M})$ (two-way ANOVA followed by the Tukey post hoc test).
Control

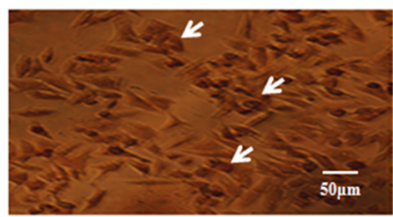

Rhein $(200 \mu \mathrm{M})$

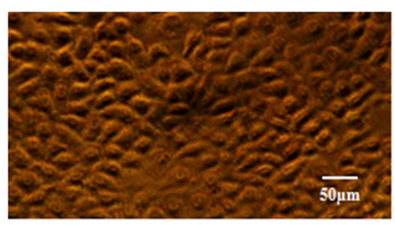

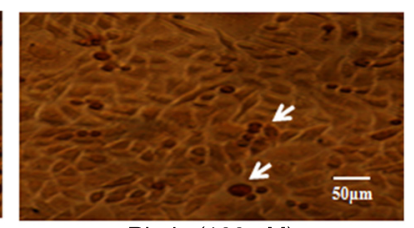
Rhein $(100 \mu \mathrm{M})$

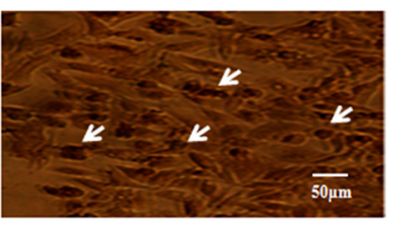

Rhein $(300 \mu \mathrm{M})$
Figure 2. Cell apoptosis observed using TUNEL staining. SGC7901 cells were treated with rhein $(0,100,200$, or $300 \mu \mathrm{M})$ for 48 h. Apoptotic cells exhibited morphological changes in the nuclei typical of apoptosis. Photographs were taken under an inverted microscope (scale bar, $50 \mu \mathrm{m}$ ). Arrows indicate apoptotic cells. 
The number of apoptotic SGC-7901 cells (shown in dark brown, white arrows) increased with the dose of rhein. Apoptotic SGC-7901 cells displayed a round and shrunken cell body, suggesting that rhein-induced apoptosis of SGC7901 cells might contribute to reduced cell viability.

To further quantify rhein-induced apoptosis of SGC7901 cells, cells were stained with annexin V-FITC and $\mathrm{PI}$, followed by flow cytometry. A representative result of flow cytometry is presented in Figure 3A. The lower right quadrant depicts the percentage of early apoptotic cells (annexin V-FITC-stained cells) and the upper right quadrant represents the percentage of late apoptotic cells (annexin V-FITC- and PI-stained cells). The fully apoptotic cells are those in the lower right and upper right quadrants. As shown in the quantitative result in Figure 3B, only a small number of apoptotic cells was detected in the control group. However, $48 \mathrm{~h}$ after treatment with 100,200 , and $300 \mu \mathrm{M}$ rhein, cell apoptosis was 7.3, 21.9, and 43.5\%, respectively. This result suggests that rhein induced significant apoptosis of SGC-7901 cells in a dose-dependent manner.

\section{Rhein increased mRNA expression of caspase- 3 and -9}

Real-time quantitative PCR was used to detect the mRNA expression of caspase-3 and -9 at $48 \mathrm{~h}$ after rhein treatment at concentrations of $0,100,200$, or $300 \mu \mathrm{M}$. The change in mRNAexpression was normalized by GAPDH expression. The result showed that the mRNA expression of caspase-3 and -9 increased significantly after treatment with rhein for $48 \mathrm{~h}$ and the up-regulation exhibited a rhein dose-dependent pattern (Figure 4).

\section{Rhein increased Bax but decreased \\ $\mathrm{Bcl}-2, \mathrm{Bcl}-\mathrm{xL}$ and pro-caspase-3 expression in SGC-7901 cells}

Western blot analysis was used to further detect protein expressions of $\mathrm{Bcl}-2, \mathrm{Bax}, \mathrm{Bcl}-$ $\mathrm{xL}$, and pro-caspase-3 in SGC-7901 cells $48 \mathrm{~h}$ after rhein $(0,100,200$, and $300 \mu \mathrm{M})$ treatment. $\beta$-actin was used as an internal loading control. The Bax and $\mathrm{Bcl}-2$ ratio is generally used as an indicator of the extent of cell apoptosis since an increased Bax:Bcl-2 ratio suggests an increased disruption of the nucleus. In the present study, rhein treatment increased Bax protein expression while it decreased $\mathrm{Bcl}-2$ protein expression in treated SGC-7901 cells (Figure 5A). The quantitative result for the $\mathrm{Bax}: \mathrm{Bcl}-2$ ratio showed a dose-dependent effect of rhein.
Indeed, 48-h incubation with $300 \mu \mathrm{M}$ rhein increased the Bax:Bcl-2 ratio 16.32-fold (Figure 5A), suggesting that significant amount of apoptosis had occurred in SGC-7901 cells in the presence of a high concentration of rhein. In contrast, 48-h rhein incubation decreased the protein levels of Bcl-xL and pro-caspase-3 to 23.2 and $25.7 \%$ of the control level, respectively (Figure $5 \mathrm{~B}$ and $\mathrm{C}$ ). The effect of rhein on regulating the expression of apoptosis-related proteins further supported the observation of rhein-induced apoptosis in SGC-7901 cells.

Rhein induced apoptosis in SGC-7901 cells possibly via a mitochondrial pathway by increasing the expression
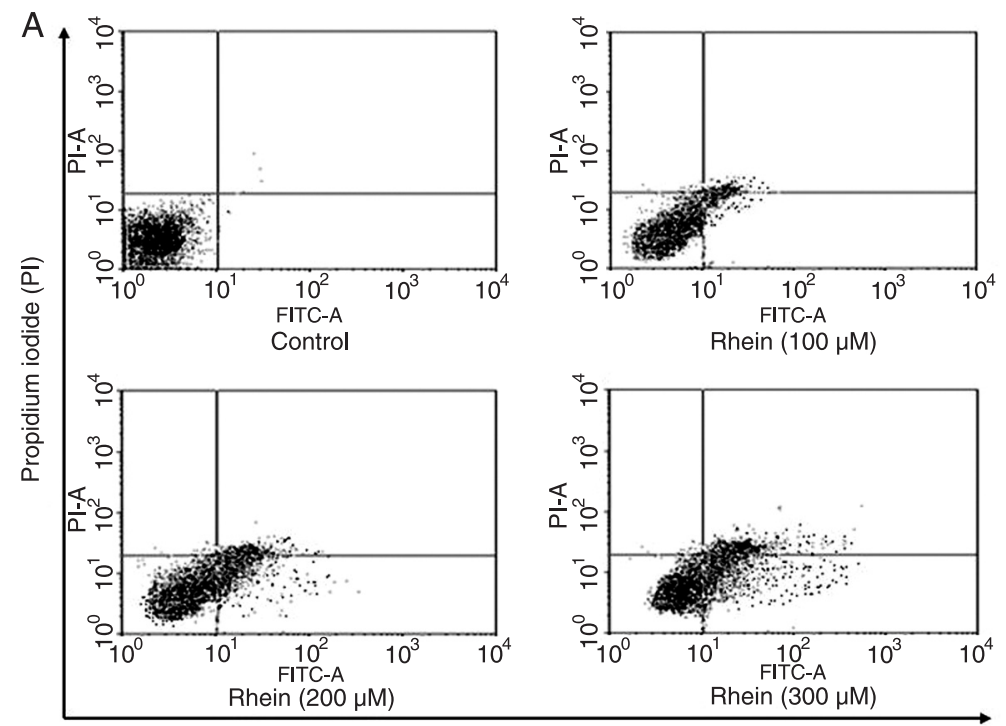

B

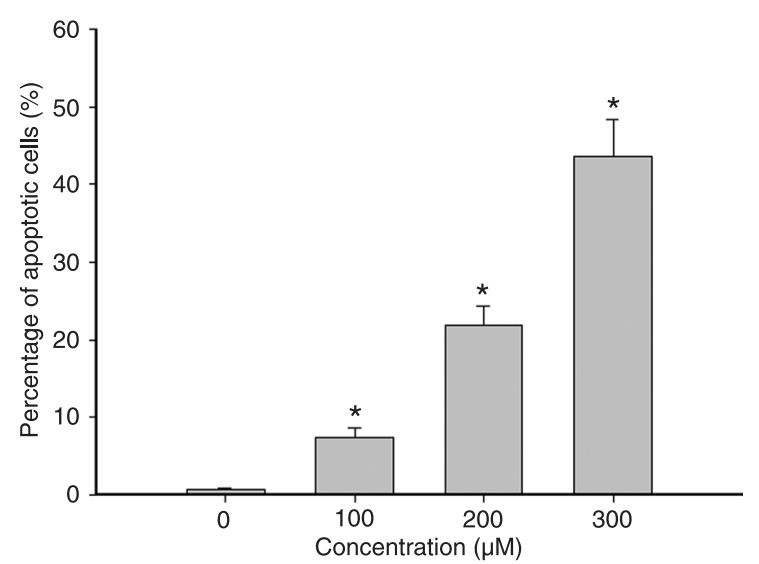

Figure 3. Rhein-induced apoptosis in SGC-7901 cells was determined by flow cytometry using the annexin FITC-PI staining method. The cells were treated with rhein $(0,100,200$, or $300 \mu \mathrm{M})$ for $48 \mathrm{~h}$. The lower right quadrant indicates the percentage of early apoptotic cells (FITC-stained cells) and the upper right quadrant indicates the percentage of late apoptotic cells (FITC-PI-stained cells) $(A)$. The experiment was repeated three times and the percentage of apoptotic cells (means \pm SEM) for each treatment group is shown in $B$. ${ }^{*} P<0.05$ versus control group $(0 \mu \mathrm{M})$ (one-way ANOVA followed by the Tukey post hoc test). 


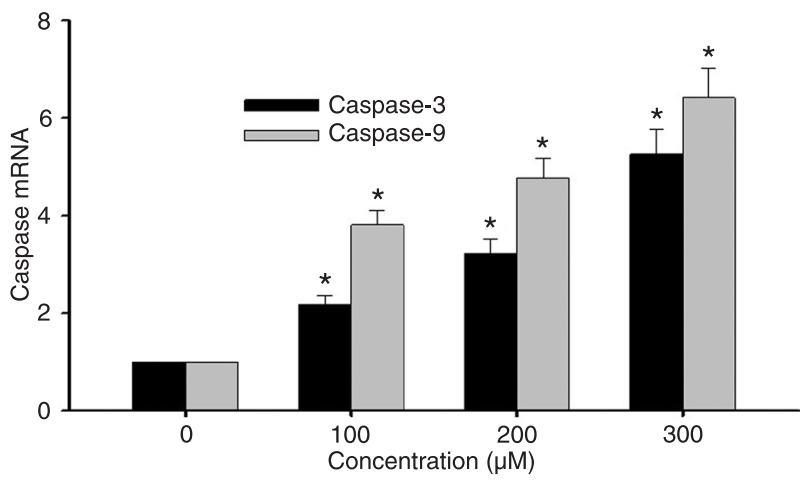

Figure 4. Rhein increased gene expression of caspase-9 and -3 in SGC-7901 cells in a dose-dependent manner. SGC-7901 cells were treated with rhein $(0,100,200$, or $300 \mu \mathrm{M})$ for $48 \mathrm{~h}$. The expression of mRNAs was analyzed by real-time quantitative PCR and normalized by GAPDH expression. ${ }^{*} P<0.05$ versus control group $(0 \mu \mathrm{M})$ (two-way ANOVA followed by the Tukey post hoc test). of cytochrome c and Apaf-1.

During apoptosis, cytochrome $\mathrm{c}$ is released from the mitochondria into the cytoplasm, and then acts on Apaf-1 by increasing the binding of Apaf- 1 to ATP/dATP. Upon binding to cytochrome $c$ and dATP, Apaf-1 forms an oligomeric apoptosome. The apoptosome then binds and cleaves caspase- 9 preprotein and this process further stimulates the subsequent caspase cascade that commits the cell to apoptosis. To investigate whether a mitochondrial pathway is involved in rhein-induced apoptosis of SGC-7901 cells, we used Western blot to detect the expression of cytochrome c and Apaf-1 proteins in SGC-7901 cells after a 48-h rhein treatment. Our result showed that rhein significantly increased the expression of cytochrome $c$ and Apaf-1 in SGC-7901 cells in a dose-dependent manner (Figure 6A and B). SGC-7901 cells incubated with $300 \mu \mathrm{M}$ rhein for $48 \mathrm{~h}$ showed a 3.73- and 4.12-fold increase in cytochrome $c$ and Apaf-1, respectively. This result indicated that rheininduced up-regulation of cytochrome $\mathrm{c}$ and Apaf- 1 might

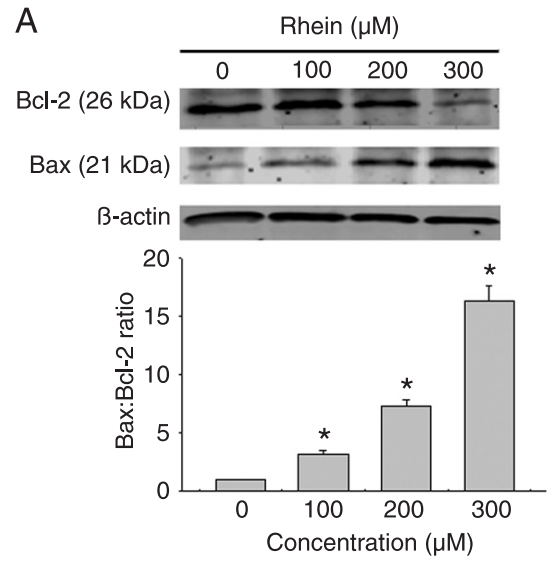

B
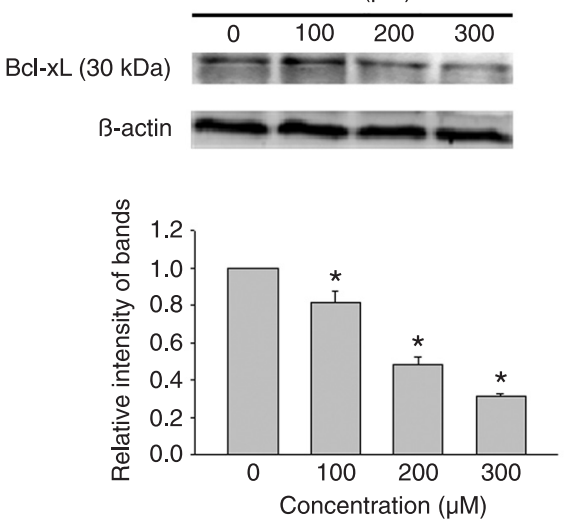

Figure 5. Rhein decreased the expression of $\mathrm{Bcl}-2$, Bcl-xL and pro-caspase-3 but increased the expression of the proapoptotic protein Bax in SGC-7901 cells. SGC-7901 cells were treated with rhein $(0,100,200$, or $300 \mu \mathrm{M})$ for $48 \mathrm{~h}$ and the expression of proteins in treated cells was determined by Western blot analysis. A, Rhein-induced changes in $\mathrm{Bcl}-2$ and Bax expression and $\mathrm{Bax}: \mathrm{Bcl}-2$ ratio. $B$, Rhein decreased Bcl-xL. $C$, Rhein decreased pro-caspase-3. Data are reported as the means \pm SEM of at least three experiments. ${ }^{*} \mathrm{P}<0.05$ versus control group $(0 \mu \mathrm{M})$ (two-way ANOVA followed by the Tukey post hoc test).
C

\section{Rhein $(\mu \mathrm{M})$}

$0 \quad 100 \quad 200$

Pro-caspase-3 (34 kDa)
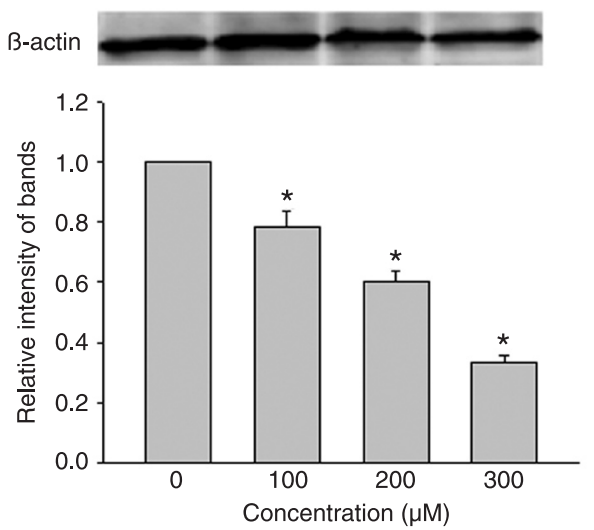
A
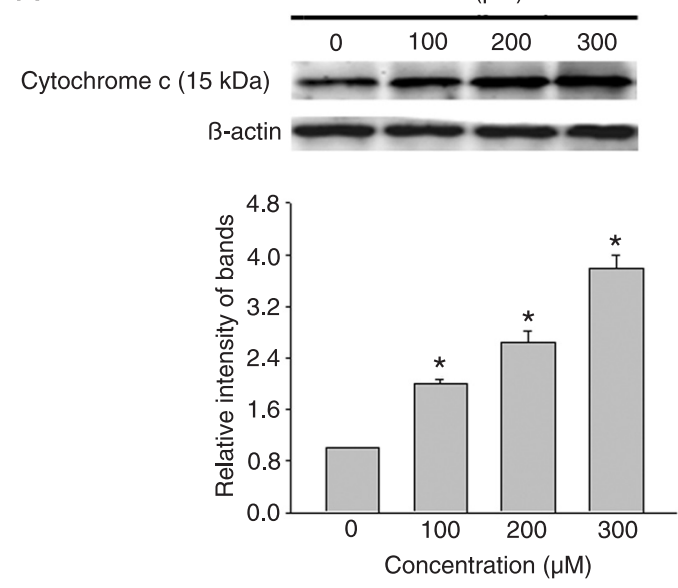

B
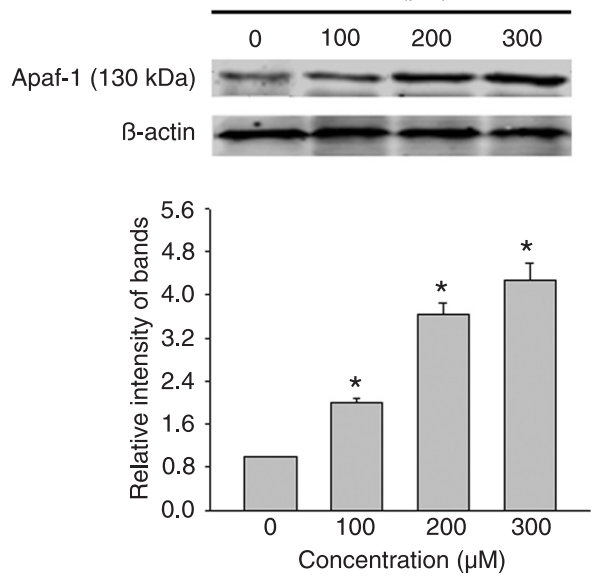

Figure 6. Treatment with rhein increased the expression of cytochrome $c$ and Apaf-1 in SGC-7901 cells. SGC-7901 cells were treated with rhein $(0,100,200$, or $300 \mu \mathrm{M})$ for $48 \mathrm{~h}$ and protein levels of cytochrome $\mathrm{c}(A)$ and Apaf-1 $(B)$ were determined by Western blot. Data are reported as the means \pm SEM of at least three experiments. ${ }^{*} \mathrm{P}<0.05$ versus control group $(0 \mu \mathrm{M})$ (one-way ANOVA followed by the Tukey post hoc test).

contribute to apoptosis of SGC-7901 cells, suggesting that a mitochondrial pathway is involved in the antitumor effect of rhein in SGC-7901 cell lines.

\section{Discussion}

In this study, we examined for the first time the effect of rhein on the human gastric cancer cell line SGC-7901. We observed a dose- and time-dependent anti-proliferation effect of rhein on these cells. Rhein induced apoptosis of SGC-7901 cells possibly by regulating the expression of apoptotic proteins including $\mathrm{Bcl}-2$, Bax and $\mathrm{Bcl}-\mathrm{xL}$. The rhein-induced apoptosis might be mediated by the activation of a mitochondrial pathway increasing the expression of cytochrome $c$ and Apaf-1.

The effect of rhein-induced apoptosis has been previously reported in other cell types $(11,15-18)$. Apoptosis is a physiological mechanism for killing cancer cells without causing damage to normal cells or surrounding tissues (19). Thus, induction of apoptosis in cancer cells is a key mechanism by which anticancer therapy works (20). In the present study, we also observed an anti-proliferation effect of rhein on SGC-7901 cells by the induction of apoptosis and this effect exhibited a dose- and time-dependent pattern.

\section{Rhein-induced apoptosis is mediated by a mitochondrial pathway}

There are two major pathways that could induce apoptosis: an extrinsic pathway and an intrinsic pathway. In the intrinsic pathway, many factors such as environmental changes, stimuli and drugs could induce mitochondrial dysfunction. Cytochrome $\mathrm{c}$ is released from dysfunctional mitochondria and accumulates in the cytoplasm where it binds to the protein Apaf-1. Binding of pro-caspase- 9 to Apaf-1 oligomers results in the formation of an apoptosome, eventually leading to the activation of caspase-3, DNA damage and cell apoptosis $(21,22)$. Many molecules are involved in this process of apoptosis, and among these proteins the $\mathrm{Bcl}-2$ family plays important roles in apoptosis and is considered to be a target for anticancer therapy $(23,24)$. Bcl-2 and Bcl-xL suppress apoptosis, while Bax is a pro-apoptotic protein in the Bcl-2 family $(25,26)$. An increased $\mathrm{Bax} / \mathrm{Bcl}-2$ ratio is associated with apoptosis. In the present study, we observed a rhein-induced increase in the Bax/Bcl-2 ratio, which was accompanied by alterations in apoptosis-associated gene expression. This result further supports the apoptotic effect of rhein on gastric cancer cells. When the Bax/Bcl-2 protein ratio is increased, the caspases become fragmented $(27,28)$, transmembrane pores form across the outer mitochondrial membrane, Bax leads to loss of membrane potential (29), and cytochrome $\mathrm{c}$ is released from the mitochondria and accumulates in the cytoplasm where it binds to Apaf-1 (30). Meanwhile, pro-caspase- 9 binds to Apaf-1 oligomers, resulting in the formation of apoptosome (31), which leads to the activation of caspase-3, and then to DNA damage and cell apoptosis $(21,22,32-34)$. A previous study has shown that rhein inhibits proliferation of human airway smooth muscle cells (35) and induces apoptosis in human cervical cancer Ca Ski cells (16) via a mitochondria-dependent pathway. Therefore, it is of interest to determine whether a mitochondrial pathway also contributes to rhein-induced apoptosis in gastric cancer cells. Our data showed that rhein induced up-regulation of cytochrome c and Apaf-1 in SGC-701 cells, and these 
alterations are concurrent with changes in apoptosis-related genes including caspase-9, -3, Bax, Bcl-2, Bcl-xL, and pro-caspase-3, suggesting the involvement of an intrinsic mitochondrial pathway in rhein-induced apoptosis in gastric cancer cells.

\section{The anticancer effect of rhein may be mediated by other signal pathways}

Inducing apoptosis is an important but not the only pathway whereby rhein may exert its antitumor effect on cancer cells. Studies have shown that rhein induces G1/S and G0/G1 cell cycle arrest through inhibition of cyclin D3, Cdk4 and Cdk6, thus increasing the efficacy of cancer chemotherapy (14). Other studies have shown that rhein inhibits the expression of matrix metalloproteinase-2 (MMP-2) and MMP-9 by modulation of the nuclear factor kappa B activation pathway and decreases the expression of vascular endothelial growth factor, suggesting a role of rhein in inhibiting migration and invasion of cancer cells

\section{References}

1. Jemal A, Thomas A, Murray T, Thun M. Cancer statistics, 2002. CA Cancer J Clin 2002; 52: 23-47.

2. Thun MJ, DeLancey JO, Center MM, Jemal A, Ward EM. The global burden of cancer: priorities for prevention. Carcinogenesis 2010; 31: 100-110.

3. Lin S, Li JJ, Fujii M, Hou DX. Rhein inhibits TPA-induced activator protein-1 activation and cell transformation by blocking the JNK-dependent pathway. Int J Oncol 2003; 22: 829-833.

4. Huang Q, Lu G, Shen HM, Chung MC, Ong CN. Anti-cancer properties of anthraquinones from rhubarb. Med Res Rev 2007; 27: 609-630.

5. Miccadei S, Pulselli R, Floridi A. Effect of lonidamine and rhein on the phosphorylation potential generated by respiring rat liver mitochondria. Anticancer Res 1993; 13: 15071510.

6. Delpino A, Paggi MG, Gentile PF, Castiglione S, Bruno T, Benass $M$, et al. Protein synthetic activity and adenylate energy charge in Rhein-treated cultured human glioma cells. Cancer Biochem Biophys 1992; 12: 241-252.

7. Castiglione S, Fanciulli M, Bruno T, Evangelista M, Del Carlo C, Paggi MG, et al. Rhein inhibits glucose uptake in Ehrlich ascites tumor cells by alteration of membrane-associated functions. Anticancer Drugs 1993; 4: 407-414.

8. Lai WW, Yang JS, Lai KC, Kuo CL, Hsu CK, Wang CK, et al. Rhein induced apoptosis through the endoplasmic reticulum stress, caspase- and mitochondria-dependent pathways in SCC-4 human tongue squamous cancer cells. In Vivo 2009; 23: 309-316

9. Chen YY, Chiang SY, Lin JG, Yang JS, Ma YS, Liao CL, et al. Emodin, aloe-emodin and rhein induced DNA damage and inhibited DNA repair gene expression in SCC-4 human tongue cancer cells. Anticancer Res 2010; 30: 945-951.

10. Chen YY, Chiang SY, Lin JG, Ma YS, Liao CL, Weng SW, et al. Emodin, aloe-emodin and rhein inhibit migration and invasion in human tongue cancer SCC-4 cells through the
$(10,13)$. The antitumor effect of rhein on gastric cancer in vivo and the possible underlying molecular mechanism require further study, while rhein has the potential to be developed as a chemotherapeutic or adjuvant agent for human gastric cancer.

\section{Potential clinical application of rhein}

In this study, we used up to $200 \mu \mathrm{M}$ rhein to induce cell apoptosis. This concentration is high but within the range used by other researchers $(15,36)$. The wide range of rhein concentrations might be due to the different tolerance of different cell lines used in these studies. Rhein has long been used by Chinese people as an oral medicine and has proven to be an effective medicine for liver and gastric system protection, but so far no research has been done to show the minimal effective plasma concentration in human subjects. Our results, together with data reported by others, will provide a clinical reference for the rhein dosage. However, further studies need to be done. inhibition of gene expression of matrix metalloproteinase-9. Int J Oncol 2010; 36: 1113-1120.

11. Aviello G, Rowland I, Gill Cl, Acquaviva AM, Capasso $F$, McCann M, et al. Anti-proliferative effect of rhein, an anthraquinone isolated from Cassia species, on Caco-2 human adenocarcinoma cells. J Cell Mol Med 2010; 14: 2006-2014.

12. Lin YJ, Zhen YS. Rhein lysinate suppresses the growth of breast cancer cells and potentiates the inhibitory effect of Taxol in athymic mice. Anticancer Drugs 2009; 20: 65-72.

13. Lin ML, Chung JG, Lu YC, Yang CY, Chen SS. Rhein inhibits invasion and migration of human nasopharyngeal carcinoma cells in vitro by down-regulation of matrix metalloproteinases- 9 and vascular endothelial growth factor. Oral Oncol 2009; 45: 531-537.

14. Hsia TC, Yang JS, Chen GW, Chiu TH, Lu HF, Yang MD, et al. The roles of endoplasmic reticulum stress and $\mathrm{Ca}^{2+}$ on rhein-induced apoptosis in A-549 human lung cancer cells. Anticancer Res 2009; 29: 309-318.

15. Shi P, Huang Z, Chen G. Rhein induces apoptosis and cell cycle arrest in human hepatocellular carcinoma BEL-7402 cells. Am J Chin Med 2008; 36: 805-813.

16. Ip SW, Weng YS, Lin SY, Mei D, Tang NY, Su CC, et al. The role of $\mathrm{Ca}^{2+}$ on rhein-induced apoptosis in human cervical cancer Ca Ski cells. Anticancer Res 2007; 27: 379-389.

17. Lin S, Fujii M, Hou DX. Rhein induces apoptosis in HL-60 cells via reactive oxygen species-independent mitochondrial death pathway. Arch Biochem Biophys 2003; 418: 99-107.

18. Kuo PL, Hsu YL, Ng LT, Lin CC. Rhein inhibits the growth and induces the apoptosis of Hep G2 cells. Planta Med 2004; 70: 12-16.

19. Evan GI, Vousden KH. Proliferation, cell cycle and apoptosis in cancer. Nature 2001; 411: 342-348.

20. Kaufmann SH, Earnshaw WC. Induction of apoptosis by cancer chemotherapy. Exp Cell Res 2000; 256: 42-49.

21. Slee EA, Harte MT, Kluck RM, Wolf BB, Casiano CA, 
Newmeyer DD, et al. Ordering the cytochrome c-initiated caspase cascade: hierarchical activation of caspases-2, -3 , $-6,-7,-8$, and -10 in a caspase-9-dependent manner. J Cell Biol 1999; 144: 281-292.

22. Lee HJ, Lee HJ, Lee EO, Ko SG, Bae HS, Kim CH, et al. Mitochondria-cytochrome C-caspase-9 cascade mediates isorhamnetin-induced apoptosis. Cancer Lett 2008; 270: 342-353.

23. Baell JB, Huang DC. Prospects for targeting the Bcl-2 family of proteins to develop novel cytotoxic drugs. Biochem Pharmacol 2002; 64: 851-863.

24. Goodsell DS. The molecular perspective: $\mathrm{Bcl}-2$ and apoptosis. Stem Cells 2002; 20: 355-356.

25. Kluck RM, Bossy-Wetzel E, Green DR, Newmeyer DD. The release of cytochrome $c$ from mitochondria: a primary site for Bcl-2 regulation of apoptosis. Science 1997; 275: 11321136.

26. Sedlak TW, Oltvai ZN, Yang E, Wang K, Boise LH, Thompson $\mathrm{CB}$, et al. Multiple Bcl-2 family members demonstrate selective dimerizations with Bax. Proc Natl Acad Sci U S A 1995; 92: 7834-7838.

27. Oltvai ZN, Milliman CL, Korsmeyer SJ. Bcl-2 heterodimerizes in vivo with a conserved homolog, Bax, that accelerates programmed cell death. Cell 1993; 74: 609-619.

28. Mantena SK, Baliga MS, Katiyar SK. Grape seed proanthocyanidins induce apoptosis and inhibit metastasis of highly metastatic breast carcinoma cells. Carcinogenesis 2006; 27: 1682-1691.
29. Green DR, Reed JC. Mitochondria and apoptosis. Science 1998; 281: 1309-1312.

30. Li P, Nijhawan D, Budihardjo I, Srinivasula SM, Ahmad M, Alnemri ES, et al. Cytochrome $c$ and dATP-dependent formation of Apaf-1/caspase- 9 complex initiates an apoptotic protease cascade. Cell 1997; 91: 479-489.

31. Hengartner MO. The biochemistry of apoptosis. Nature 2000; 407: 770-776.

32. Thornberry NA, Lazebnik Y. Caspases: enemies within. Science 1998; 281: 1312-1316.

33. Dvorakova K, Payne CM, Landowski TH, Tome ME, Halperin DS, Dorr RT. Imexon activates an intrinsic apoptosis pathway in RPMI8226 myeloma cells. Anticancer Drugs 2002; 13: 1031-1042.

34. Hess CJ, Berkhof J, Denkers F, Ossenkoppele GJ, Schouten $\mathrm{JP}$, Oudejans JJ, et al. Activated intrinsic apoptosis pathway is a key related prognostic parameter in acute myeloid leukemia. J Clin Oncol 2007; 25: 1209-1215.

35. Heo SK, Yun HJ, Park WH, Park SD. Rhein inhibits TNFalpha-induced human aortic smooth muscle cell proliferation via mitochondrial-dependent apoptosis. J Vasc Res 2009; 46: 375-386.

36. Lin ML, Chen SS, Lu YC, Liang RY, Ho YT, Yang CY, et al. Rhein induces apoptosis through induction of endoplasmic reticulum stress and $\mathrm{Ca}^{2+}$-dependent mitochondrial death pathway in human nasopharyngeal carcinoma cells. Anticancer Res 2007; 27: 3313-3322. 